Pacific Journal of Mathematic 


\title{
TWO PROPERTIES OF THE SORGENFREY PLANE
}

\author{
William G. BADE
}

\begin{abstract}
The Sorgenfrey line $S$ is the real line with the topology generated by the half open intervals $[a, b)$. R. H. Sorgenfrey proved that $S$ is paracompact, while $S \times S$ is not paracompact, or even normal. The two main results of this paper are that $S \times S$ is strongly zero-dimensional, and that every real continuous function on $S \times S$ is in the first Baire class for the Euclidean topology of the plane. These results answer questions asked by $P$. Nyikos.
\end{abstract}

Interest in $S \times S$ arises from the important problem of whether the product of strongly zero-dimensional spaces is strongly zerodimensional. The proof given for $S \times S$ shows the difficulties which are involved in settling the general case. On the other hand, the algebra $C_{b}(S \times S)$ of all bounded continuous functions on $S \times S$ is an interesting example of a function algebra related to the Baire classes. Its structure space $\beta(S \times S)$ is shown to be totally disconnected.

Since this paper was written we have learned that the strong zero-dimensionality of $S^{2}$ was proved independently and simultaneously by Mrowka [3] and by two pairs: P. Nyikos-P. Roy and R. HeathD. Lutzer (their proofs will appear in a paper written by Nyikos). Mrowka [3] proved that each continuous function on $S^{n}$ ( $n$ an arbitrary cardinal) is of the first Baire class for the Euclidean topology. Recently Mrowka [4] has proved the strong zero-dimensionality of $S^{n}$ for every cardinal $n$. In presenting this paper we claim no priority for the results, as we find they had been announced prior to submission of our paper. However, we believe that the proofs given here are conceptually very simple and intuitive.

1. Strong zero-dimesionality. Following Nyikos [5] we call a completely regular space $X$ totally disconnected if no connected set has more than one point, and zero-dimensional if it has a base of clopen (=open and closed) sets. We say $X$ is strongly zero-dimensional if given any two disjoint zero sets $Z_{1}$ and $Z_{2}$ in $X$ there exists a clopen set $C$ such that $Z_{1} \subseteq C, Z_{2} \cap C=\phi$. For compact spaces these properties are all equivalent (see [1], page 247, where the term "zero-dimensional" is used for "strongly zero-dimensional"). The following general theorem is known. (See [5] where further equivalent conditions are given.)

THEOREM 1.1. Let $X$ be completely regular. The following conditions are equivalent: 
(i) $X$ is strongly zero-dimensional.

(ii) $\beta(X)$ is totally disconnected.

(iii) Every cozero set in $X$ is a countable of clopen sets.

The Sorgenfrey plane $S \times S$ has as base for its topology the clopen boxes $[a, b) \times[c, d)$. If $p=(x, y) \in S \times S$ and $\sigma>0$ we write $B(p, \sigma)=[x, x+\sigma) \times[y, y+\sigma)$ and call it the clopen square cornered at $p$ with side $\sigma$. In what follows, there will be an interplay between the Sorgenfrey and Euclidean topologies of the plane. We denote these topologies by $\mathscr{S}$ and $\mathscr{E}$ respectively. Thus int ${ }_{\mathscr{C}}(A)$ means the Euclidean interior of $A, \operatorname{cl}_{\mathscr{S}}(A)$ is the closure of $A$ for $\mathscr{S}$, etc. The term clopen always refers to $\mathscr{S}$.

The Sorgenfrey plane is a zero-dimensional completely regular space. To get a feeling for its asymmetrical character, note that the relative topology on any line with negative slope is discrete, while a line with positive slope is homeomorphic in its relative topology to $S$. The Sorgenfrey line $S$ is strongly zero-dimensional [5]. We shall prove that $S \times S$ is strongly zero-dimensional by establishing (iii) above. Our first task is to determine a sufficiently large class of clopen sets in $S \times S$. The clopen boxes are insufficient, since there are obvious clopen sets such as the triangle

$$
x+y \geqq 1, \quad 0<x<1, \quad 0<y<1
$$

which are not countable unions of clopen boxes. We give a way of generating clopen sets from $\mathscr{E}$-compact sets.

LeMma 1.2. Let $K$ be $\mathscr{E}$-compact, $\sigma>0$ and

$$
W=\bigcup_{p \in K} B(p, \sigma) \text {. }
$$

If $K \cap \operatorname{int}_{\mathscr{B}}(W)=\phi$, then $W$ is clopen.

Proof. Clearly $W$ is $\mathscr{S}$-open. We show it is $\mathscr{S}$-closed. Suppose that $q_{0}$ is a point of $W^{c}$ such that every clopen square $B\left(q_{0}, \varepsilon\right)$ intersects $W$. Taking $\varepsilon=1 / n$, we can find a sequence of points $q_{n} \in$ $B\left(q_{0}, 1 / n\right) \cap W$. Then $\left\{q_{n}\right\}$ converges to $q_{0}$ for both $\mathscr{E}$ and $\mathscr{S}$. Now $q_{n} \in B\left(p_{n}, \sigma\right)$, where $\left\{p_{n}\right\}$ is a sequence of points in $K$. Without loss of generality we can suppose $\left\{p_{n}\right\}$ converges for $\mathscr{E}$ to a point $p_{0} \in K$, and that the Euclidean distance of each $p_{n}$ from $p_{0}$ is less than $\sigma / 2$. Then $q_{0} \in \operatorname{cl}_{\mathscr{\&}} B\left(p_{0}, \sigma\right)$. Since $q_{0} \notin W$, it must lie on one of the two open sides of $B\left(p_{0}, q\right)$.

Suppose without loss of generality that $q_{0}$ lies on the upper open side; i.e., $q=\left(x, y_{0}+\sigma\right)$ where $p_{0}=\left(x_{0}, y_{0}\right)$ and $0 \leqq x \leqq x_{0}+\sigma$. We investigate where the points $p_{n}$ must lie. 
(1) No $p_{n}=\left(x_{n}, y_{n}\right)$ can have $y_{n} \leqq y_{0}$. For no neighborhood $B\left(q_{0}, \varepsilon\right)$ could contain a point $q_{n}$.

(2) No $p_{n}$ lies in $\operatorname{int}_{c} B\left(p_{0}, \sigma\right)$, since then $K \cap \operatorname{int}_{\mathscr{B}}(W) \neq \phi$.

(3) It must be true then that for all $n$

$$
\begin{aligned}
& x_{0}-\sigma<x_{n} \leqq x_{0}, \\
& y_{0}<y_{n}<y_{0}+\sigma, \quad n=1,2, \cdots .
\end{aligned}
$$

However, since $p_{n} \rightarrow p_{0}$ for $\mathscr{E}$, the horizontal line segment

$$
\left(t, y_{0}+\sigma\right), \quad x_{0} \leqq t<x_{0}+\sigma,
$$

lies in $\bigcup_{n=1}^{\infty} B\left(p_{n}, \sigma\right)$. Thus unless $q_{0}=\left(x_{0}+\sigma, y_{0}+\sigma\right)$, we would have $q_{0} \in W$.

(4) If $q_{0}=\left(x_{0}+\sigma, y_{0}+\sigma\right)$, then by (3) for each $\varepsilon>0, B\left(q_{0}, \varepsilon\right) \cap$ $B\left(p_{n}, \sigma\right)=\phi$. Thus no such square $B\left(q_{0}, \varepsilon\right)$ can contain a point $q_{n}$.

These cases show that it is impossible that $p_{n} \rightarrow p_{0}$, and we have the required contradiction.

The condition on $K$ cannot be dropped. For example take $K$ to be the segment $x=y, 0 \leqq x \leqq 1$, and $\sigma=1$. The point $(1,0)$ is an $\mathscr{S}$-limit point of $\bigcup_{k \in K} B(k, 1)$ but is not a member of this set.

THEOREM 1.3. Let $V$ be any S-open set in $S \times S$. There exists a sequence $\left\{Q_{n}\right\}$ of clopen sets such that

$$
V \cong \bigcup_{n=1}^{\infty} Q_{n} \leqq \mathrm{cl}_{\mathscr{S}} V
$$

Proof. It is clearly sufficient to consider the case where $V$ is bounded for $\mathscr{E}$. Let $\sigma>0$ and define

$$
A_{\sigma}=\left\{p \in \operatorname{cl}_{\mathscr{S}} V \mid B(p, \sigma) \leqq \mathrm{cl}_{\mathscr{S}} V\right\} \text {. }
$$

Then $A_{o}$ is $\mathscr{E}$-compact. For let $a_{n} \in A, a_{n} \rightarrow a_{0}$ for $\mathscr{E}$. We have

$$
\text { int } B\left(a_{0}, \sigma\right) \subseteq \bigcup_{n=1}^{\infty} B\left(a_{n}, \sigma\right) \subseteq \mathrm{cl} V \text {. }
$$

Thus $B\left(a_{\vartheta}, \sigma\right) \subseteq \mathrm{cl} ; V$, so $a_{0} \in A_{\sigma}$. Now define

$$
K_{\sigma}=A_{\sigma} \sim \operatorname{int}_{\delta}\left(\mathrm{cl}_{\circlearrowleft} V\right)
$$

and

$$
W_{\sigma}=\bigcup_{k \in K_{\sigma}} B(k, \sigma) \text {. }
$$

Then $K_{\sigma}$ is $\mathscr{E}$-compact, and

$$
K_{\sigma} \cap \operatorname{int}_{\mathscr{S}} W_{\sigma}=\dot{\phi} .
$$

It follows from Lemma 1.2 that $W_{\sigma}$ is clopen. 
We prove now that $V$ can be covered by a sequence of clopen sets contained in $\operatorname{cl}_{\mathscr{S}} V$. First suppose that $p \in V \sim \operatorname{int}_{\mathscr{C}}\left(\mathrm{cl}_{\mathscr{S}} V\right)$. Since $V$ is $\mathscr{S}$-open, there exists $\delta>0$ such that $B(p, \delta) \subseteq V$. Thus $p \in K_{\delta} \subseteq W_{\delta}$. If $\delta_{1}<\delta_{2}$ we have $K_{\delta_{1}} \subseteq K_{\delta_{2}}$. Thus

$$
V \sim \operatorname{int}_{\mathscr{E}}\left(\mathrm{cl}_{\mathscr{S}} V\right) \subseteq \bigcup_{n=1}^{\infty} K_{1 / n} \leqq \bigcup_{n=1}^{\infty} W_{1 / n} \leqq \mathrm{cl}_{\mathscr{S}} V
$$

Further $\operatorname{int}_{\mathscr{E}}\left(\operatorname{cl}_{\mathscr{S}} V\right)$ is open for $\mathscr{E}$, and hence is the union of a sequence $\left\{Z_{n}\right\}$ of clopen boxes. Letting $Q_{n}=Z_{n} \cup W_{1 / n}$, we have

$$
V \cong \bigcup_{n=1}^{\infty} Q_{n} \subseteq \operatorname{cl}_{\mathscr{S}} V
$$

An open set $U$ for $\mathscr{S}$ is called regular if $U=\operatorname{int}_{\mathscr{S}}\left(\mathrm{cl}_{\mathscr{S}} U\right)$.

COROLLARY 1.4. Every regular open set in $S \times S$ is a countable union of clopen sets, and hence a cozero set.

Theorem 1.3 also solves the problem of strong zero-dimensionality for $S \times S$.

THEOREM 1.5. The Sorgenfrey plane is strongly zero-dimensional.

Proof. We verify (iii) of Theorem 1.1. Let $U$ be a cozero set in $S \times S$. Then $U=\bigcup_{n=1}^{\infty} U_{k}$ where each $U_{k}$ is a cozero set with

$$
U_{k} \subseteq \operatorname{cl}_{\mathscr{S}} U_{k} \subseteq U_{k+1} \text {. }
$$

By Theorem 1.3 each $U_{k}$ has a countable cover by clopen sets contained in $U$, so $U$ is a countable union of clopen sets.

In the proof of Theorem 1.5 the Euclidean topology seems to play an essential role in several ways-particularly in identifying clopen sets in the product other than the obvious clopen boxes. Any attack on the general problem of whether the class of strongly zerodimensional spaces is closed under products must surmount this difficulty of providing a rich source of clopen sets.

Finally we give an example of an open set in $S \times S$ which is not a countable union of clopen sets. Let $U$ be the "open" triangle $x+y>1,0<x<1,0<y<1$ together with those points on the hypotenuse whose coordinates are irrational. Then $U$ is $\mathscr{S}$-open. If $U$ were a countable union of clopen sets it would be a cozero set. It follows from Theorem 2.1 below that $U$ would be an $F_{\sigma}$ set for $\mathscr{E}$, i.e., $U=\bigcup_{n=1}^{\infty} K_{n}$ where each $K_{n}$ is $\mathscr{E}$-compact. This is impossible, since the set of irrationals on the diagonal is not itself an $F_{\sigma}$ set. 
2. Baire measurability. The following result answers a question asked by P. Nyikos' ${ }^{1}$.

THEOREM 2.1. Every $\mathscr{S}$-continuous real function $f$ on $S \times S$ is in the first Baire class for the Euclidean topology of the plane.

Proof. For a point $p=(x, y) \in S \times S$, let

$$
C(p, \sigma)=[x, x+\sigma] \times[y, y+\sigma]
$$

be the closed square of side $\sigma$ cornered at $p$. The continuity of $f$ on $S \times S$ can be expressed by the condition that for each $p \in S \times S$ and $\varepsilon>0$, there exists a closed square $C(p, \delta)$ such that

$$
|f(q)-f(p)|<\varepsilon, \text { if } q \in C(p, \delta) .
$$

We first show that $f$ is Lebesgue measurable. Let $\varepsilon>0$ be fixed and let $\mathscr{F}$ be the collection of all closed squares $C(p, \delta)$, for points $p \in S \times S$ such that relation (\#) holds. The collection $\mathscr{F}$ covers the plane in the sense of Vitali. Thus by the Vitali Covering Theorem (as in [2], page 366) there exists a disjoint sequence $\left\{C_{n}\right\} \subseteq \mathscr{F}$ such that

$$
m\left((S \times S) \sim \bigcup_{n=1}^{\infty} C_{n}\right)=0,
$$

where $m$ is Lebesgue measure. Define the function $g$ on $\bigcup_{n=1}^{\infty} C_{n}$ as follows: if $C_{n}=C(p, \delta)$, let

$$
g(q)=f(p), \quad q \in C_{n} .
$$

At other points let $g(p)=0$. Then $g$ is Lebesgue (in fact Borel) measurable and

$$
|g(p)-f(p)|<\varepsilon
$$

almost everywhere for $m$. Taking successively $\varepsilon=1 / n$, we obtain that $f$ is almost everywhere the uniform limit of Borel measurable functions, and hence Lebesgue measurable.

Now for each $n$ let $G_{n}=\{q \| f(q) \mid \leqq n\}$, and define the averaging functions

$$
h_{n}(p)=n^{2} \int_{\sigma(p, 1 / n)} f(q) k_{G_{n}}(q) \mathrm{dm}, \quad n=1,2, \cdots .
$$

Then $h_{n}$ is $\mathscr{E}$-continuous. Because $f$ is $\mathscr{S}$-continuous

$$
\lim _{n \rightarrow \infty} h_{n}(p)=f(p), \quad p \in S \times S,
$$

so $f$ is of the first Baire class.

1 In Problem 40 from the Mathematics Problem Book of Carnegie-Mellon University he asks whether such $f$ are Borel measurable. 


\section{REFERENCES}

1. L. Gillman and M. Jerison, Rings of Continuous Functions, Princeton, 1960.

2. E. J. McShane, Integration, Princeton, 1947.

3. S. Mrowka, Some problems releted to $N$-compact spaces, to appear.

4. - All powers of the Sorgenfrey space are strongly 0-dimensional, to appear. 5. P. Nyikos, Not every 0-dimensional real compact space is $N$-compact, Bull. Amer. Math. Soc., 77 (1971), 392-396.

6. R. H. Sorgenfrey, On the topological product of paracompact spaces, Bull. Amer. Math. Soc., 53 (1947), 631-632.

Received January 13, 1972 and in revised form November 1, 1973. The research in this paper was supported by the National Science Foundation under Grant GP-22712.

UNIVERSITY OF CALIFORNIA, BERKELEY 


\section{PACIFIC JOURNAL OF MATHEMATICS}

\section{EDITORS}

RICHARD ARENS (Managing Editor)

University of California

Los Angeles, California 90024
J. DUGUNDJI*

Department of Mathematics

University of Southern California

Los Angeles, California 90007

D. Gilbarg and J. Milgram

Stanford University

Stanford, California 94305
University of Washington

Seattle, Washington 98105

ASSOCIATE EDITORS
E. F. BECKENBACH
B. H. NeumanN
F. WoLF
K. YosHIDA

\section{SUPPORTING INSTITUTIONS}

\author{
UNIVERSITY OF BRITISH COLUMBIA \\ CALIFORNIA INSTITUTE OF TECHNOLOGY \\ UNIVERSITY OF CALIFORNIA \\ MONTANA STATE UNIVERSITY \\ UNIVERSITY OF NEVADA \\ NEW MEXICO STATE UNIVERSITY \\ OREGON STATE UNIVERSITY \\ UNIVERSITY OF OREGON \\ OSAKA UNIVERSITY
}

\author{
UNIVERSITY OF SOUTHERN CALIFORNIA \\ STANFORD UNIVERSITY \\ UNIVERSITY OF TOKYO \\ UNIVERSITY OF UTAH \\ WASHINGTON STATE UNIVERSITY \\ UNIVERSITY OF WASHINGTON
* * * *
AMERICAN MATHEMATICAL SOCIETY \\ NAVAL WEAPONS CENTER
}

The Supporting Institutions listed above contribute to the cost of publication of this Journal, but they are not owners or publishers and have no responsibility for its content or policies.

Mathematical papers intended for publication in the Pacific Journal of Mathematics should be in typed form or offset-reproduced, (not dittoed), double spaced with large margins. Underline Greek letters in red, German in green, and script in blue. The first paragraph or two must be capable of being used separately as a synopsis of the entire paper. Items of the bibliography should not be cited there unless absolutely necessary, in which case they must be identified by author and Journal, rather than by item number. Manuscripts, in duplicate if possible, may be sent to any one of the four editors. Please classify according to the scheme of Math. Rev. Index to Vol. 39. All other communications to the editors should be addressed to the managing editor, or Elaine Barth, University of California, Los Angeles, California, 90024.

100 reprints are provided free for each article, only if page charges have been substantially paid. Additional copies may be obtained at cost in multiples of 50 .

The Pacific of Journal Mathematics is issued monthly as of January 1966. Regular subscription rate: $\$ 72.00$ a year (6 Vols., 12 issues). Special rate: $\$ 36.00$ a year to individual members of supporting institutions.

Subscriptions, orders for back numbers, and changes of address should be sent to Pacific Journal of Mathematics, 103 Highland Boulevard, Berkeley, California, 94708.

PUBLISHED BY PACIFIC JOURNAL OF MATHEMATICS, A NON-PROFIT CORPORATION

Printed at Kokusai Bunken Insatsusha (International Academic Printing Co., Ltd.), 270, 3-chome Totsuka-cho, Shinjuku-ku, Tokyo 160, Japan.

* C. R. DePrima California Institute of Technology, Pasadena, CA 91109, will replace J. Dugundji until August 1974.

Copyright (C) 1973 by Pacific Journal of Mathematics

Manufactured and first issued in Japan 


\section{Pacific Journal of Mathematics}

\section{Vol. 51, No. $2 \quad$ December, 1974}

Robert F. V. Anderson, Laplace transform methods in multivariate spectral theory .................................................. 339

William George Bade, Two properties of the Sorgenfrey plane . . . . . . . . . . . . 349

John Robert Baxter and Rafael Van Severen Chacon, Functionals on continuous

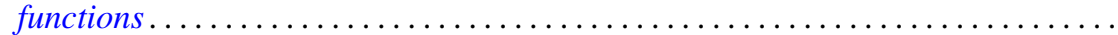

Phillip Wayne Bean, Helly and Radon-type theorems in interval convexity

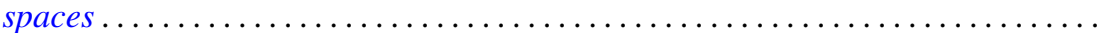

James Robert Boone, On k-quotient mappings $\ldots \ldots \ldots \ldots \ldots \ldots \ldots \ldots \ldots$

Ronald P. Brown, Extended prime spots and quadratic forms . . . . . . . . . . . .

William Hugh Cornish, Crawley's completion of a conditionally upper continuous lattice .............................................

Robert S. Cunningham, On finite left localizations ...................

Robert Jay Daverman, Approximating polyhedra in codimension one spheres

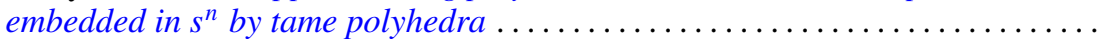

Burton I. Fein, Minimal splitting fields for group representations . . . . . . . . . . . .

Peter Fletcher and Robert Allen McCoy, Conditions under which a connected

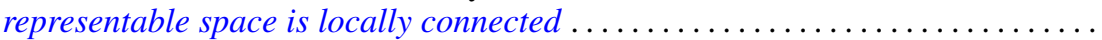

Jonathan Samuel Golan, Topologies on the torsion-theoretic spectrum of a noncommutative ring...

Manfred Gordon and Edward Martin Wilkinson, Determinants of Petrie matrices.

Alfred Peter Hallstrom, A counterexample to a conjecture on an integral condition for determining peak points (counterexample concerning peak points)........

E. R. Heal and Michael Windham, Finitely generated $F$-algebras with applications to Stein manifolds.

Denton Elwood Hewgill, On the eigenvalues of a second order elliptic operator in an unbounded domain ............................

Charles Royal Johnson, The Hadamard product of $A$ and $A^{*}$.

Darrell Conley Kent and Gary Douglas Richardson, Regular completions of Cauchy spaces.

Alan Greenwell Law and Ann L. McKerracher, Sharpened polynomial approximation

Bruce Stephen Lund, Subalgebras of finite codimension in the algebra of analytic functions on a Riemann surface. .

Robert Wilmer Miller, TTF classes and quasi-generators . .

Roberta Mura and Akbar H. Rhemtulla, Solvable groups in which every maximal partial order is isolated ....

Isaac Namioka, Separate continuity and joint continuity...

Alan Saleski, Entropy of self-homeomorphisms of statistical pseudo-metric

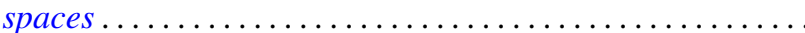

H. A. Seid, Cyclic multiplication operators on $L_{p}$-spaces .....

H. B. Skerry, On matrix maps of entire sequences ............

John Brendan Sullivan, A proof of the finite generation of invariants of a normal

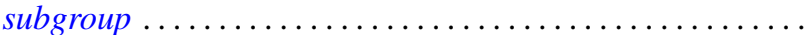

John Griggs Thompson, Nonsolvable finite groups all of whose local subgroups are

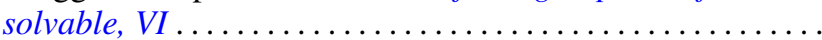

